\title{
Formulation of High Fiber Breakfast Food and Estimation of its Functional Qualities
}

\author{
SABITRI SHARMA* and BHUPENDRA PAUDYAL
}

\author{
National College of Food Science and Technology, Khusibu, Kathmandu, Nepal
}

This study aims to develop high fiber breakfast food rich in nutritional and functional components ( $\beta$-glucan, antioxidants, and insoluble fiber) and identify the future possibilities of commercial product. Based on the 15 days survey carried out on Kathmandu, an optimum formulation (86\% cereal, 5\% nuts, $7 \%$ dried fruits and 2\% pumpkin seed) of product was found at first 3 trails.

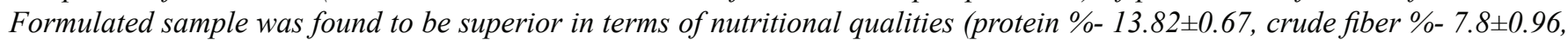

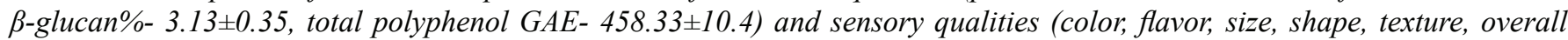
acceptance) than market sample (Protein\%- $12.39 \pm 1.54$, crude fiber\%- 5.18 \pm 0.9 , $\beta$-glucan\%- $1.18 \pm 0.07$, total polyphenol GAE$163.3 \pm 58.6)$. The product was further developed by varying processing methods (germinating, non-germinating wheat and instant $\left(60^{\circ} \mathrm{C}\right)$ and gradual drying $\left.\left(50^{\circ} \mathrm{C}, 55^{\circ} \mathrm{C}, 60^{\circ} \mathrm{C}, 70^{\circ} \mathrm{C}\right)\right)$. Formulation having germinated wheat and instant dried $\left(60^{\circ} \mathrm{C}\right)$ was found to be superior in terms of color, texture, flavor and overall acceptance. The product was further subjected to chemical and functional analysis, cost analysis (Rs.42), microbiological analysis (TPC-1.8x103, Yeast count- 400cfu/g, Mold count- 300cfu/g), storage stability test $\left(a_{w=}\right.$ 0.113). Statistical analysis showed no significance difference among products of varying drying pattern but difference among germinated and non-germinated products. Consumer perceptibility test showed $64 \%$ of the consumer accepted muesli as the best product than commercial breakfast cereals.

Keywords: Muesli, High fibre, Functional components, Water activity

\section{Introduction}

Functional food can be defined as "any healthy food claimed to have a health-promoting or disease-preventing property beyond the basic function of supplying nutrients" (Roberfroid, 2000). Breakfast cereals are generally high in carbohydrate and are low in fat; some have high bran contents, and many contain appreciable amounts of certain vitamins and minerals, partially satisfying the mineral and vitamin requirements (Gibson and Gunn, 2011). Dietary fiber and antioxidants are the major functional constituents of breakfast cereal. More recently, soluble fiber such as $\left(1^{\prime} ! 3,1^{\prime} ! 4\right)-\beta$-D-glucan has been shown to have effects on the immune function, insulin, and cholesterol level in the human body (Chantaro et al., 2007).

Muesli is relatively new type of breakfast cereals in case of Nepal carrying functional properties. Muesli is defined as a mixture of cereals (esp. rolled oats), dried fruit, and nuts, typically eaten with milk and yoghurt at breakfast. They are rich in fiber, antioxidants and healthy fat (Golay et al., 1991).

Ingredients of muesli depend on the availability of raw materials. They generally include cereals (Wheat, barley, oats, sorghum, brown rice), nuts, dried fruits etc. (Swaminathan, 2003, Kent and Evers, 2004, Lobato et al., 2010). Brown rice contains high fiber in comparison with white rice and is a source of vitamins also (McKevith, 2004). Pumpkin seeds are the source of omega-3-fattty acids which is beneficial in prevention of cardiovascular disease and cholesterol lowering effect (Joshi et al., 2002; Stevenson et al., 2007). Carrot is the source of natural antioxidants and soluble fiber (Chau et al., 2003). Nuts are the source of protein, good fat and antioxidants (Zhang et al., 2009).

\footnotetext{
*Corresponding author, E-mail: sabitrisharma7@gmail.com
}

The average chemical composition of the muesli is protein $11 \%$, lipid $6.2 \%$, dietary fiber $6.7 \%$, sugar $20 \%$ and energy value $287 \mathrm{Kcal}$ (Golay et al., 1991). The study showed that the consumption rate (Approx.40\%) and product awareness (Approx. 25\%) of muesli in Nepal is very low. Hence, introduction of muesli like product will have a greater significance in Nepalese food market in coming days.

\section{Materials and Methods}

Preliminary study on raw materials was carried out to determine the type of raw material to be used in the product. It was done through different literatures and personal communications.

All raw materials were processed separately depending upon their different characteristics. After shaping final product they were subjected to following analyses.

Chemical analysis- The chemical analysis of product was done on proximate analysis (AOAC, 2005), total sugar and reducing sugar (AOAC, 2005), beta glucans (Rhee et al., 2007), total polyphenol content (Iqbal et al., 2005), microbiological analysis for its total plate count, mold count and yeast count (Manandhar and Sharma, 2006) and water activity (Isopiestic method, Rahman et al., 2001).

Sensory evaluation- The products were performed by 9 point hedonic scoring test $(9=$ like extremely, $1=$ dislike extremely) for color, size, shape, flavor, texture, and overall acceptance. The evaluation was carried out by 12 semi-trained panelists. Similarly, consumer perceptibility test of product was performed by taking 50 consumers as an analyst.

Statistical analysis- Data on physicochemical and sensory analysis were tabulated for comparison and were graphically 
represented using Microsoft Excel-2007, Data were statistically processed by GenStat Discovery Edition 4.

\section{Results and Discussion}

Market survey of breakfast cereals- 15 different departmental stores and 20 consumers were asked to know about the status of the product in the market and its scope in the future. $40 \%$ people come back saying that they ate breakfast and then another $60 \%$ saying that they didn't eat breakfast. $40 \%$ people know about the muesli and every $25 \%$ people know about the health benefits of the products. Average rate of products sale was 50-60 packet/month.
Trail Formulations and physiochemical analysis- Three samples were made as a trial sample with varying proportion of ingredients i.e. increasing cereal content and decreasing nuts and fruit portion in the product. Proximate and functional properties of the products were determined and compared with market sample followed by the cost analysis and sensory analysis. Proximate and functional compositions of products are given in Table 1.

Decrease in protein, fat and ash content in the product is due to the low percentage of nuts and fruits available in the product. Crude fiber content and beta glucan content of the formulated samples were higher than the market sample may be due to the addition of high fiber ingredients in the products like wheat,

Table 1. Chemical composition of products of trial formulations

\begin{tabular}{ccccc}
\hline Parameters & A & B & C & M \\
Moisture, \% & $4.71 \pm 0.37$ & $4.87 \pm 0.81$ & $6.17 \pm 0.57$ & $4.61 \pm 0.34$ \\
& & & & \\
Protein, \% & $20.02 \pm 0.54$ & $17.1 \pm 1.11$ & $13.82 \pm 0.67$ & $12.39 \pm 1.54$ \\
Fat, \% & $15.64 \pm 1.84$ & $10.19 \pm 3.28$ & $5.96 \pm 1.28$ & $5.91 \pm 1.55$ \\
Ash, \% & $1.63 \pm 0.06$ & $1.49 \pm 0.11$ & $1.21 \pm 0.12$ & $1.86 \pm 0.06$ \\
Crude Fiber, \% & $7.43 \pm 1.02$ & $7.47 \pm 1.25$ & $7.8 \pm 0.96$ & $5.18 \pm 0.9$ \\
$\quad$ Total & & & & \\
Carbohydrate, \% & $50.56 \pm 1.64$ & $58.88 \pm 3.55$ & $65.03 \pm 2.3$ & $70.04 \pm 3.44$ \\
Beta Glucan & $3.51 \pm 0.3$ & $3.06 \pm 0.37$ & $3.13 \pm 0.35$ & $1.18 \pm 0.07$ \\
Total Polyphenol & & & & \\
(WS), GAE & $183.3 \pm 20.81$ & $286.7 \pm 15.2$ & $458.33 \pm 10.4$ & $163.3 \pm 58.6$ \\
Total Polyphenol & & & & \\
(MS), GAE & $621.7 \pm 7.6$ & $362.7 \pm 2.5$ & $415 \pm 13.2$ & $515 \pm 5$ \\
Energy Value, Kcal & $423.09 \pm 10.29$ & $395.69 \pm 22.36$ & $369.11 \pm 5.22$ & $382.99 \pm 5.63$ \\
\hline
\end{tabular}

Note: Values are averages of triplicate determination \pm s. d., Sample A $=68 \%$ cereals, $B=83 \%$ cereals $C=86 \%$ cereals containing syrup coated samples and $\mathrm{M}$ is the market sample of same type, $\mathrm{GAE}=$ Gallic Acid Equivalent $(\mathrm{mg} / \mathrm{kg}), \mathrm{MS}=$ methanol soluble, $\mathrm{WS}=$ Water soluble.

brown rice, sorghum and oat flakes. Total polyphenol content of the formulated sample was higher than the market sample as formulated samples contained higher proportion of polyphenol containing ingredients i.e. nuts, pumpkin seeds etc. The energy value obtained was higher than the commercial value in every formulation which satisfied the aim of formulation of products which was further supported by Golay et al., (1991), energy value of muesli is estimated to be around $287 \mathrm{Kcal}$. According to Golay et al., (1991), Protein content of the muesli is $11 \%$, lipid $6.2 \%$, dietary fiber $6.7 \%$, sugar $20 \%$ and energy value 287 Kcal.

Based upon the functional characteristics like low fat, appropriate protein, high energy value, high fiber (Soluble and insoluble), high total polyphenol and lowest cost, formulation- $\mathrm{C}$ was found to be the best product whose proportions were used for further product developments.
Sensory analysis of trial formulations- By evaluating sensory quality of the product one best product was selected that contained $86 \%$ cereals, $5 \%$ nuts, $7 \%$ dried fruits and $2 \%$ pumpkin seeds. The order of superiority in terms of color, size, shape, texture, flavor and overall acceptance of the products with varying proportion of ingredients can be summarized below;

Color: Sample C > Sample B $>$ Sample A

Size: Sample C $>$ Sample A $>$ Sample B

Shape: Sample C $>$ Sample A $>$ Sample B

Texture: Sample C $>$ Sample B $>$ Sample A

Flavor: Sample C $>$ Sample A $>$ Sample B

Overall acceptance: Sample C $>$ Sample A $>$ Sample B

It showed that product-C got highest score on all the sensory attributes. So the product-C was accepted for the further analysis and formulation. Product $\mathrm{C}$ further developed to study 
the treatment techniques to improve color, texture, flavor and overall acceptance of the products.

Product formulations with varying treatments and physiochemical analysis- Four different samples of same proportion of ingredients but with varying treatment technique were designed. The prepared products were subjected to chemical, physical, and microbiological analysis. The chemical composition of the product having different treatment techniques are tabulated in the Table 2.
Treatment method involved were germinated/non germinated, gradual dried/instant dried. The LSD testing of the product showed that there was no significant difference $(\mathrm{p}<0.05)$ within the formulated samples but was different with market samples in terms of moisture, protein, fat, ash, crude fiber, total carbohydrate, total polyphenol, total sugar. But there showed significant difference within the samples in terms of reducing sugar and beta glucan whereas market sample was significantly difference with formulated products in all ways

Table 2. Chemical compositions of products with varying treatment methods

\begin{tabular}{cccccc}
\hline Parameters & $\mathbf{C}$ & $\mathbf{D}$ & $\mathbf{E}$ & $\mathbf{F}$ & $\mathbf{M}$ \\
\hline Moisture, \% & $6.17 \pm 0.57^{\mathrm{a}}$ & $5.02 \pm 0.11^{\mathrm{bc}}$ & $5.70 \pm 0.55^{\mathrm{ab}}$ & $5.43 \pm 0.49^{\mathrm{ab}}$ & $4.61 \pm 0.34^{\mathrm{c}}$ \\
Protein, \% & $13.82 \pm 0.67^{\mathrm{a}}$ & $13.81 \pm 0.91^{\mathrm{a}}$ & $14.83 \pm 1.31^{\mathrm{a}}$ & $13.38 \pm 3.5^{\mathrm{a}}$ & $12.39 \pm 1.54^{\mathrm{a}}$ \\
Fat, \% & $5.96 \pm 1.28^{\mathrm{ab}}$ & $6.3 \pm 1^{\mathrm{ab}}$ & $6.73 \pm 0.93^{\mathrm{ab}}$ & $7.36 \pm 1.04^{\mathrm{b}}$ & $5.91 \pm 1.55^{\mathrm{ac}}$ \\
Ash, \% & $1.21 \pm 0.12^{\mathrm{a}}$ & $1.35 \pm 0.40^{\mathrm{a}}$ & $1.10 \pm 0.08^{\mathrm{a}}$ & $1.11 \pm 0.1^{\mathrm{a}}$ & $1.86 \pm 0.06^{\mathrm{b}}$ \\
Crude Fiber, \% & $7.8 \pm 0.96^{\mathrm{a}}$ & $8.32 \pm 0.85^{\mathrm{a}}$ & $8.9 \pm 1.34^{\mathrm{a}}$ & $7.83 \pm 0.66^{\mathrm{a}}$ & $5.18 \pm 0.9^{\mathrm{b}}$ \\
$\quad$ Total & & & & \\
Carbohydrate, \% & $65.03 \pm 2.3^{\mathrm{a}}$ & $65.18 \pm 2.28^{\mathrm{a}}$ & $62.72 \pm 1.88^{\mathrm{a}}$ & $64.87 \pm 3.28^{\mathrm{a}}$ & $70.04 \pm 3.44^{\mathrm{b}}$ \\
Beta Glucan, \% & $3.13 \pm 0.35^{\mathrm{a}}$ & $3.4 \pm 0.43^{\mathrm{a}}$ & $4.1 \pm 0.7^{\mathrm{b}}$ & $3.26 \pm 0.21^{\mathrm{a}}$ & $1.18 \pm 0.07^{\mathrm{c}}$ \\
Total Polyphenol & & & & \\
$\quad$ WS), GAE & $458.3 \pm 10.4^{\mathrm{a}}$ & $375 \pm 5^{\mathrm{b}}$ & $496.3 \pm 3.2^{\mathrm{a}}$ & $371 \pm 1.7^{\mathrm{b}}$ & $163 \pm 58.6^{\mathrm{c}}$ \\
Total Polyphenol & & & & \\
$\quad$ MS), GAE & $415 \pm 13.2^{\mathrm{a}}$ & $415 \pm 13.2^{\mathrm{a}}$ & $510 \pm 10^{\mathrm{b}}$ & $426 \pm 3.6^{\mathrm{a}}$ & $515 \pm 5^{\mathrm{b}}$ \\
Energy Value, Kcal & $369.11 \pm 5.22^{\mathrm{a}}$ & $372.67 \pm 5.29^{\mathrm{a}}$ & $370.82 \pm 8.81^{\mathrm{a}}$ & $379.41 \pm 4.5^{\mathrm{b}}$ & $382.99 \pm 5.63^{\mathrm{b}}$ \\
Reducing Sugar, \% & $16.23 \pm 0.81^{\mathrm{ac}}$ & $9.3 \pm 0.3^{\mathrm{b}}$ & $17.22 \pm 0.32^{\mathrm{a}}$ & $15 \pm 0.5^{\mathrm{c}}$ & $8.82 \pm 1.28^{\mathrm{b}}$ \\
$\quad$ Total Sugar, \% & $38.63 \pm 1.68^{\mathrm{a}}$ & $36.36 \pm 2.01^{\mathrm{a}}$ & $36.08 \pm 2.37^{\mathrm{ab}}$ & $32.33 \pm 2.86^{\mathrm{b}}$ & $14.85 \pm 0.87^{\mathrm{c}}$ \\
\hline
\end{tabular}

Note: Values are averages of triplicate determination \pm s. d.; Sample $\mathrm{C}=$ Germinated, Gradual dried, $\mathrm{D}=\mathrm{Non}$ Germinated, constant dried, $\mathrm{E}=$ Germinated, Constant dried, $\mathrm{F}=$ none germinated, gradual dried and $\mathrm{M}$ is the market sample of same type. $\mathrm{LSD}=$ Least Significant Difference, GAE = Gallic Acid equivalent $(\mathrm{mg} / \mathrm{kg}), \mathrm{MS}=$ methanol soluble, WS= water soluble. Values followed by same superscripts within same row are not significantly different $(\mathrm{p}<0.05)$.

(chemical composition and nutritional value). LSD testing showed that there was no significant effect of germination and drying on chemical composition of product.

\section{Sensory Analysis of formulations having varying treatments-}

Sensory evaluation was done with semi trained panelists on 9 point hedonic rating scale. Statistical analysis showed that there was no effect of germination on sensory qualities like texture, color and flavor while there was significant effect of drying on flavor and overall acceptance of the products. The order of superiority in terms of color, size, shape, texture, flavor and overall acceptance of the all products with varying treatment techniques can be summarized as;

Color: Sample F $>$ Sample C $=$ Sample D $>$ Sample E

Size: Sample E $=$ Sample C $>$ Sample D $>$ Sample F

Shape: Sample E > Sample C > Sample F > Sample D

Texture: Sample E $=$ Sample D $>$ Sample C $>$ Sample F

Flavor: Sample E $>$ Sample F $>$ Sample D $>$ Sample C

Overall acceptance: Sample E $>$ Sample F $>$ Sample D > Sample C
From the superiority pattern above in effect of varying treatment on the sensory quality it was found the product E (Germinated, constant temperature dried) scored highest in terms of color, flavor, size, shape, texture and overall acceptance in comparison to other products. So the product E was accepted as a best product in terms of sensory quality.

Consumer perceptibility test of product- Finalized product scoring highest score through sensory analysis was subjected to consumer perceptibility test in comparison with popular market breakfast food by taking 50 consumers as an analyst and $64 \%$ of consumer accepted muesli in comparison to other commercial products.

Microbial analysis- Microbiological analysis showed TPC of the product in the range of $1.8 \times 10^{3}$ to $3.0 \times 10^{3} \mathrm{cfu} / \mathrm{g}$ and Yeast mold were in the range of 200 to $400 \mathrm{cfu} / \mathrm{g}$ which are within the range given to breakfast cereals which is supported by Deibel and Katherine, 2001 where TPC of the breakfast cereals/snacks food are given at the range of $1-10^{3} \mathrm{cfu} / \mathrm{g}$, molds were at the range of $1-10^{3}$ and yeasts of $1-10^{2} \mathrm{cfu} / \mathrm{g}$ in the range. 
Water activity determination- The loss or gain pattern of weight of product samples is shown in Figure 1.

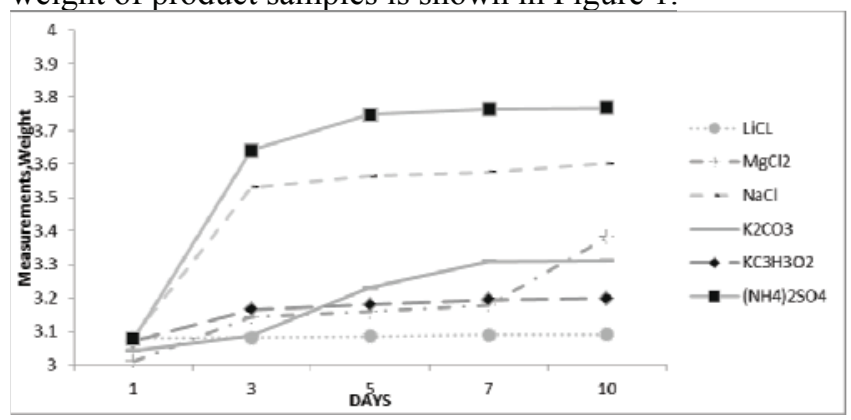

Figure1. Days vs. weight of samples in different saturated solution containing vessel

Figure 1, it showed that weight of products line in saturated solution of $\mathrm{LiCl}$ remained straight in comparison to other vessel sample where very little gain in weight of sample occurred. As the water activity of saturated solution of $\mathrm{LiCl}$ is 0.113 at all the temperature, the water activity of the sample remained 0.113 at all temperature. So, the product can be regarded as a low moisture food and can be stored for a long period of time.

\section{Conclusion}

The study was conducted to know the status of product and future possibilities of product in Nepali market and then to design breakfast cereal rich in functional characteristics. 15 days of survey carried out in local market of Kathmandu on Muesli showed that $40 \%$ people know muesli and only $25 \%$ know about the health benefits of product and it can be made using locally available raw materials in pilot plant scale. Three trial samples were prepared and compared with market sample of same type. There was significant effect of proportion of ingredients. With the increase in proportion of cereals and decrease in nuts and fruits proportion in the product protein, fat, ash and energy value decreases and beta glucan, total polyphenol and crude fiber increase and increase the sensory quality of the product. Formulated samples were found to be superior in terms of nutritional qualities like protein \%- $13.82 \pm 0.67$, Crude fiber \%- 7.8 \pm 0.96 , beta glucan $\%-3.13 \pm 0.35$, total polyphenol GAE- $458.33 \pm 10.4$ and sensory qualities (color, flavor, size, shape, texture, overall acceptance) than market sample (Protein\%- $12.39 \pm 1.54$, crude fiber $\%$ - $5.18 \pm 0.9$, beta glucan\%- $1.18 \pm 0.07$, total polyphenol GAE- 163.3 \pm 58.6 ).

Further experiment showed there was less significant effect of treatment techniques on the nutritional quality and sensory quality of the products. Germinated and constant dried product was found to best in comparison to non germinated and gradual dried product in terms of sensory qualities (shape, size, texture, flavor, overall acceptance). Optimization of proportion of ingredients reveals that around $86 \%$ cereals, $5 \%$ nuts, $7 \%$ dried fruits and $2 \%$ pumpkin seed is optimum proportion of ingredients which is better than the existing local product. With the varying treatment techniques there was not such significant difference (in sensory and chemical composition value) within the formulated samples except reducing sugar.

\section{References}

AOAC, (2005). Official Methods of Analysis of AOAC International, $18^{\text {th }}$ Edition, AOAC International, Washington DC.

Chantaro P., Devahastin S. and Chiewchan N. (2008). Production of antioxidant high dietary fiber powder from carrot peels. J. Food Sci. and Tech. 41: 1987-1994

Chau C. F., Chen C. H. and Lee M. H. (2003). Comparison of the characteristics, functional properties, and in vitro hypoglycemic effects of various carrot insoluble fiberrich fractions. J. Food Sci. and Tech. 37 (2): 155-160.

Deibel K. E., Katherine M. J. (2001). $4^{\text {th }}$ Edition, Cereal and cereal products, Compendium method for the Microbial Examination of Foods, Frances Pouch Downes Keith Ito, 314, American Public Health Association.

Gibson S. A. and Gunn P. (2011). Nutritional implication of breakfast habit, British Nutrition Foundation Bulletin, 36:78-86.

Golay A., Koellreutter B., Bloise D, Assal J. P. and Wiirsch P. (1991). The effect of muesli or cornflakes at breakfast on carbohydrate metabolism in type 2 diabetic patients. J. Diabetes Res. and Clinical Practice, 15:135-142.

Iqbal S., Bhanger M. I and Anwar F. (2005). Antioxidant properties and components of bran extracts from selected wheat varieties commercially available in Pakistan. J. Nutri. and food Sci., 56: 26-34.

Joshi D. C., Das S. K., Mukherjee R. K. (2002). Physical Properties of Pumpkin Seeds. J. Agri. Eng. Res., 54 (3): 219-229.

Kent N. L and Evers A. D., (2004). Technology of cereals, $4^{\text {th }}$ edition, pp 53-78, 244-259, Woodhead publishing limited, Cambridge England.

Lobato L. P., Anibal D., Lazaretti M. M. and Grossmann M. V. E. (2010). Extruded puffed functional ingredient with oat bran and soy flour. J. Food Sci. and Tech., 44: 933-939.

Manandhar S. and Sharma S. (2006). Practical Approach to Microbiology $1^{\text {st }}$ Edition, National College, Lainchaur, 
Kathmandu, pp 83-87.

McKevith B. (2004), Nutritional aspects of cereals, British Nutrition Foundation Nutrition Bulletin, 29: 111-142.

Rahman S., Shyam S., Sablani M. and Theodore P. Labuza (2001). Measurement of Water Activity Using Isopiestic Method, Protocols in Food Analytical Chemistry, A2.3.1-A2.3.10.

Rhee J. S., Cho S.Y., Kim K.M, Cha D. S. and Park H. J. (2007). A comparative study of analytical methods for alkali-soluble $\beta$-glucan in medicinal mushroom, Chaga (Inonotus obliquus). J. Food Sci., 46: 2-8.
Roberfroid M. B. (2000). Functional food, 1st edition, Woodhead Publishing Limited, Cambrige, England.

Stevenson D. G., Fred E. J., Liping W., Lin J. J. (2007). Oil and Tocopherol Content and Composition of Pumpkin Seed Oil in 12 Cultivars, J. Agri. Food Chem., 55: 4005-4013.

Swaminathan M. (2003). Advanced Text-Book on Food and Nutrition. Vol-1. The Bangalore Printing and Publishing Co. Ltd, Mysore Road, Bangalore. pp. 539-567.

Zhang Q. A., Hui F.X., Zhang Z. Q., Zhang B. S., Zhang Z. Q. (2009). Optimization of SC-CO extraction of oil from almond pretreated with autoclaving. J. Food Sci. and Tech., 42:1530-1537. 